\title{
A Minimal Invasive Entry; Punch Tool
}

\author{
Bülent Cihantimur*, Yavuz Özsular and Özgür Ağlamiş \\ Department of Plastic Surgery, Estetik International Quasar Clinic, Turkey \\ *Corresponding Author: Bülent Cihantimur, Department of Plastic Surgery, \\ Estetik International Quasar Clinic, Turkey.
}

Received: November 27, 2020

Published: December 22, 2020

(C) All rights are reserved by Bülent

Cihantimur, et al.

\begin{abstract}
An entry point is required for minimally invasive procedures requiring access to the subcutaneous tissue on the face and in the body. Such minimally invasive procedures can be generalized as thread applications, filling applications, and fat graft applications. Keywords: Punch Tool; Needle; Flexibility
\end{abstract}

\section{Abbreviations}

PT: Punch Tool; VSS: Vancouver Scar Scale; PDO: Polydioxanone.

\section{Introduction}

These procedures are aimed to form an entry point in regions such as face, where scars are visible, allow the procedure to be done, and leave minimal scar with a good recovery period. When the literature is reviewed, it has been found that there is no specific instrument opening the entry site for such minimally invasive procedures.

Incision-opening instrument, called as Punch Tool, was designed by aiming minimal damage on the tissue entry site. The aim of the present study is to share the experiences of the case series related to this instrument.

\section{Material and Method}

The instrument called as PT has been actively used in minimally invasive procedures for more than 10 years. This instrument was used for 836 patients, including 310 patients in face lift with thread, 130 in infinity thread lift procedure, 145 in facial fat transfer, 42 in vaginal G-point filling procedure, 104 in Labium majus filling procedure, and 104 in labium majus fat graft procedure.

The researcher used $1 \mathrm{cc}$ local anesthetic containing $20 \mathrm{mg}$ lidocaine hydrochloride and $0.0125 \mathrm{mg}$ Epinephrine base in $1 \mathrm{ml}$ for the incision point, to be opened before the procedure by using a 32 $\mathrm{G}$ needle tip, waited for $2 \mathrm{~min}$., compressed the entry point between the thumb and forefinger, lifted the point $1 \mathrm{~cm}$ upwards, and then applied the procedure in such a way that the PT end would advance 1-2 mm deeper with an angle of 90 degrees.

A total of 200 patients treated with face lift with thread were divided into 2 groups including 100 patients in each in terms of the bleeding at the time of entry and also wound site recovery. After the entry site was formed from the same facial regions by using PT in 100 patients and no.11 blade scalpel in 100 patients, surgical square sponge was left over the tissue without making any pressure. Quantity of bleeding was visually monitored depending on cohesion principle (absorption of liquid molecules due to gravitational force) and after the bleeding ended, square sponge was taken. Bleeding area over square sponge was measured using a ruler. Vertical and horizontal areas were calculated, multiplied with each other, and compared in square millimeter in two patient groups.

Such a measurement type was designed because bleeding was not abundant and calculation could not be done in cc basis or gram units.

All the entry points of the patients for whom PT was used were covered with a sterile skin strip after the procedure. In patients for whom no.11 sharp scalpel tip was used, it was required to cover the entry site by using $5 / 0$ rapid vicryl at the rate of $1 \%$. 
Entry sites were examined in terms of scar development. The wound recovery of the entry points opened by using PT and no. 11 scalpel were assessed 3 months after the procedure by using Vancouver Scar Scale [1]. In the evaluation made on 4 parameters, the height, color, flexibility, and pigmentation of the scar were examined. In this scale, total score ranges between 0 and 13.0 point signifies a normal healthy skin.

\section{Statistical method}

SPSS 22 software (IBM SPSS Statistics, IBM Corporation, Chicago, IL) package program was used in the computer for statistical analysis and coding the data. Independent Samples T test was used for the significance of the difference between the two mean values. Parameters were expressed as mean \pm standard deviation (SD). It was suggested that all the values of $p<0.05$ were statistically significant.

\section{Results}

\begin{tabular}{|l|c|c|}
\hline $\begin{array}{l}\text { Vancouver } \\
\text { Scar Scoring }\end{array}$ & $\begin{array}{c}\text { Scalpel (n = 100) } \\
\text { (mean } \pm \text { SD) }\end{array}$ & $\begin{array}{c}\text { PT (n = 100) } \\
\text { (mean } \pm \text { SD) }\end{array}$ \\
\hline Vascularity & $0.92 \pm 0.45$ & $0.86 \pm 0.38^{\mathrm{z}}$ \\
\hline Pigmentation & $1.23 \pm 0.57$ & $0.54 \pm 0.37^{\mathrm{x}}$ \\
\hline Flexibility & $0.96 \pm 0.52$ & $0.94 \pm 0.44^{\mathrm{z}}$ \\
\hline Height & $0.71 \pm 0.52$ & $0.81 \pm 0.61^{\mathrm{z}}$ \\
\hline Total Score & $3.95 \pm 0.83$ & $3.12 \pm 0.72^{\mathrm{y}}$ \\
\hline
\end{tabular}

Table 1: Evaluation of skin recovery after the use of scalpel and PT methods via Vancouver Scar Score.

${ }^{x}: p<0.001,{ }^{y}: p<0.05,{ }^{z}: p>0.05$, SD: Standard deviation

Two hundred patients including 100 patients in each of Scalpel (Group 1) and PT (Group 2) methods were evaluated prospectively by using the Vancouver Scar Scoring system 12 weeks after the procedure in terms of skin recovery levels.

While the mean age of the patients was $36.2 \pm 6.3$ in Group 1, it was $35.4 \pm 5.2$ in Group 2. No significant difference was found between both groups in terms of age ( $p>0.05)$. There was no significant difference between two groups in terms of vascularity, flexibility, and height parameters ( $p>0.05)$. Pigmentation and total scores were lower in Group 2 and the difference between them was statistically significant ( $p<0.001$ and $p<0.05$, respectively) (Table 1). This result showed that PT method was more advanta- geous than the scalpel method in terms of pigmentation and thus, resulted in better skin recovery.

While calculating the square sponge of bleeding area, it was determined that there was $34 \%$ less bleeding in the study comparing the entry points opened with PT and no.11 scalpel.

\section{Discussion}

Face lift with thread procedures gain popularity every passing day. As its popularity and frequency of usage increase, new information regarding its complications and adverse effects contributes to the literature. One of the major problems in thread treatments is the formation of entry site wound scar [2].

Recovery and scar development at the entry points formed by PT and the scar development at the entry points formed by a sharpedged scalpel were evaluated 12 weeks after the operation via VSS. VSS mean score of the entry sites was lower in PT than the other group. Especially in the patients, for whom the entry point was created by using sharp tools such as scalpel, hypopigmentation developed during skin recovery and this was observed statistically at a higher rate than PT. This showed that there was a cosmetically better recovery process at the entry points formed by PT.

When the literature has been reviewed, it has been observed that there is no specific instrument for opening such an entry point. Entry points for these procedures are usually formed by using various instruments such as no.11 blade scalpel, 18-gauge needle, or sharp blade cannulas in the end of special threads [3,4]. In another study, the entry point for face lifting with barbed PDO thread was opened by using an $18 \mathrm{G}$ puncture needle [5]. In another study, needles with 3 sharp ends were used to open an entry point [6]. The use of such sharp-end instruments may cause undesirable subcutaneous injuries because the subcutaneous advancement could not be controlled by inexperienced people. The reason is that the sharp-end scalpel or needle tip are surgical instruments that are not specially designed for this procedure. Even if there is a sharp knife or end in the end of the thread, it is not a problem for experienced hands, but if the end of the thread is blunt, an entry point opening instrument will be required. PT is a surgical instrument with blunt end which is safe for subcutaneous tissue, progresses as long as force is applied to subcutaneous tissue and does not progress as long as force is not applied to subcutaneous tissue. It is controlled by the actively used hand of surgeon during penetration under skin due to its structure. 
In a study, an 11-blade scalpel or a 20-gauge needle was used to inject the graft adipose tissue to open an entry point in facial fat application [7]. In another study, an 18-gauge sharp-edged needle end with a blade was used to open an entry for fat transfer to the face [8]. Menkes., et al. used an $80 \mathrm{~mm} 18 \mathrm{G}$ cannula for labium majus micro fat filling.

The use of thin and spiky instruments especially at sensitive points such as the facial area may cause undesired injuries of the patient or the surgical team during the procedure [9]. In order to prevent such injuries, it was aimed to design an instrument with a blunt end which is also effective as much as a sharp-edged surgical instrument, due to its design.

In the study comparing the entry points opened using PT and no.11 scalpel, less bleeding was determined in the calculation of the square sponge of the bleeding area and this suggested that it caused a more minimally invasive entry point when compared to the sharp-edged instruments.

In a study, the optimization of surgical instruments saved time and money [10]. While the use of a new sharp-edged instrument during each operation every time out of its purpose imposes both time and financial burden, ready-to-use PT that is constantly present in the surgical set saves time and provides economic benefits due to being used hundreds of times for years.

\section{Conclusion}

PT, which can be fully grasped with palm due to its ergonomic structure, provides to form entry site easily and in a controlled manner without the necessity of making an effort owing to its cone-like structure stretching from a wider body to a tapping tip. The blunt tip enables a safer and minimally traumatized entry than sharp-edged entry instruments. Its metal structure, raw material, and durability are designed to allow it to be sterilized after the procedure and to be used many times for years by providing economy and time saving.

\section{Bibliography}

1. Sullivan T., et al. "Rating the burn scar". Journal of Burn Care and Rehabilitation 11 (1990): 256-260.

2. Barrett DM., et al. "Evolution of the rhytidectomy". World Journal of Otorhinolaryngology - Head and Neck Surgery 2 (2016): 38-44.
3. Kang SH., et al. "Vertical Lifting". Dermatologic Surgery 43.10 (2017): 1263-1270.

4. Unal M., et al. "Experiences of barbed polydioxanone (pdo) cog thread for facial rejuvenation and our technique to prevent thread migration". Journal of Dermatological Treatment (2019): 1-12.

5. Ali Y H. "Two years' outcome of thread lifting with absorbable barbed PDO threads: Innovative score for objective and subjective assessment". Journal of Cosmetic and Laser Therapy 20.1 (2017): 41-49.

6. Khrustaleva I., et al. "Our Technique of Thread Lifting for Facial Rejuvenation". Plastic and Reconstructive Surgery - Global Open 4.6 (2016): e739.

7. Marten T J and Elyassnia D. "Fat Grafting in Facial Rejuvenation". Clinics in Plastic Surgery 42.2 (2015): 219-252.

8. DeFatta R J and Williams E F. "Fat Transfer in Conjunction with Facial Rejuvenation Procedures". Facial Plastic Surgery Clinics of North America 16.4 (2008): 383-390.

9. Watt A M., et al. "Scalpel safety in the operative setting: A systematic review". Surgery 147.1 (2010): 98-106.

10. Crosby L., et al. "Surgical Instrument Optimization to Reduce Instrument Processing and Operating Room Setup Time". Otolaryngology-Head and Neck Surgery (2019): 019459981988563.

\section{Assets from publication with us}

- Prompt Acknowledgement after receiving the article

- Thorough Double blinded peer review

- Rapid Publication

- Issue of Publication Certificate

- High visibility of your Published work

Website: www.actascientific.com/

Submit Article: www.actascientific.com/submission.php

Email us: editor@actascientific.com

Contact us: +919182824667 